\title{
UM ESTUDO SOBRE A ADERÊNCIA DO BALANCED SCORECARD ÀS EMPRESAS ABERTAS E FECHADAS
}

\section{ADHERENCE TO THE BALANCED SCORECARD IN PUBLIC AND PRIVATE COMPANIES}

DANIEL AUGUSTO DIETSCHI

Mestre em Contabilidade e Controladoria pela Universidade do Vale do Rio dos Sinos - RS

Pesquisador da Universidade do Vale dó Rio dos Sinos - RS E-mail: daniel_dietshi@sicredi.com.br.

\author{
AUSTER"MOREIRA NASCIMENTO \\ Doutor e Mestre em Contábilidade e Controladoria pela Faculdade de \\ Economia, Administração e Contabilịdade da Universidade de São Paulo - SP \\ Professor Titular do Programa de Pós-Graduação em Ciências Contábeis da \\ Universidade do Vale do Rio dos Sinos-RS \\ E-mail: auster@unisinos.br
}

\section{RESUMO}

Diversos estudos têm apontado que a busca das empresas abertas em atender às expectativas dos acionistas pode muitas vezes ter como conseqüência a tomada.de decisões com foco no lucro imediato. Isso teria como conseqüência a perda de oportunidades de investimento em projetos mais lucrativos, com retorno a médio e longoprazo. Alguns pesquisadores entendem que esse fato pode ser sanado com o uso de instrumentos de gestão que proporcionem o equilíbrio entre aspectos financeiros e não-financeiros na empresa. Dentre esses pesquisadores, Kaplan e Norton afirmam ser essa a principal virtude do Balanced Scorecard (BSC). Considerando o problema a que esse instrumento visa a solucionar, o presente estudo buscou identificar se as suas características são mais aderentes às empresas abertas do que às fechadas. A questão foi investigada através de uma survey envolvendo a participação de executivos de 77 empresas com faturamento acima de $\mathrm{R} \$ 10$ milhões. Análises de distribuições de freqüência, testes qui-quadrado e testes Phi e Cramér's $V$ foram realizados com o apoio da ferramenta SPSS. Os resultados indicam que as características do BSC são mais aderentes às empresas abertas do que às fechadas, sendo os aspectos financeiros predominantes nas empresas com ações negociadas na Bolsa de Valores.

Palavras-chave: Balanced Scorecard. Economic Value Added. Planejamento Estratégico. Gestão de Performance. Mercado de Capitais.

\section{ABSTRACT}

Various studies have indicated that public companies' search to meet shareholder expectations can often lead to decision making with a short-term profit focus. This would lead to the loss of investment opportunities in more profitable medium and long-term return projects. Some researchers believe that this problem can be solved by using management tools that favor a balance between financial and non-financial aspects in the company. Among these researchers, Kaplan and Norton argue that this is the main virtue of the Balanced Scorecard (BSC). Considering the problem BSC intends to solve, this study aims to identify if its characteristics are more adherent to public than to private companies. The problem was investigated through a survey involving executives from 77 companies with annual revenues above $R \$ 10$ million. Frequency distribution analyses, chi-square tests and Phi and Cramér's $V$ tests were applied, with the support of SPSS software. The results indicate that BSC characteristics are more adherent to public than to private companies, with financial aspects prevailing in companies whose shares are negotiated in the Stock Exchange.

Keywords: Balanced Scorecard. Economic Value Added. Strategic Planning. Performance Management. Capital Markets. 


\section{INTRODUÇÃO}

Com o progresso do capitalismo, criou-se o conceito de Sociedade Anônima. Nessa concepção de empresa, organizações privadas, ao invés de serem propriedade de apenas um dono, ou de alguns sócios, tornaram-se propriedade de acionistas, em um sentido mais amplo. A proporção da participação de cada acionista em uma Sociedade Anônima é determinada pela quantidade de ações possuídas. As Sociedades Anônimas abertas têm suas ações negociadas livremente nos mercados de capitais.

Os mercados de capitais vêm em um processo contínuo de evolução, principalmente nas economias desenvolvidas. Segundo Weimer e Pape (1999), o valor de mercado das empresas negociadas nas Bolsas de Valores dos países anglo-saxônicos' somavam 82,1\% do seu PNB (Produto Nacional Bruto). Os países latinos ${ }^{2}$ chegam a $27,3 \%$ da referida proporção, os países germânicos ${ }^{3}$ atingem $41,7 \%$ e o Japão alcança $83,5 \%$. Em números absolutos, o mercado de capitais dos países anglo-saxônicos é maior do que o somatório dos mercados de capitais de todos os outros países citados (WEIMER; PAPE, 1999).

Diversas empresas, possivelmente conduzidas pela avidez em apresentar bons relatórios trimestrais aos acionistas, têm sido administradas com excessivo foco nos indicadores financeiros, dando pouca importância aos indicadores não-financeiros (JOHNSON; KAPLAN, 1987). Há de se considerar, entretanto, que a existência de críticas em relação à gestão baseada exclusivamente em desempenho financeiro já é tratada há muitos anos, a exemplo dos apontamentos feitos por John Dearden em $1969^{4}$.

O mencionado autor apresentou críticas à ferramenta de gestão criada no início do século XX pela DuPont e conhecida como Fórmula DuPont. A DuPont foi fundada nos EUA, no início do século XIX, como uma empresa de fabricação de pólvora, tendo criado o referido mecanismo de gestão no momento em que diversificava sua linha de produtos e buscava descentralizar sua administração, no início do século XX (DUPONT, 2005).

O modelo de gestão do desempenho da DuPont focava, basicamente, a maximização do ROI (Return On Investments) em todos os níveis hierárquicos e unidades de negócio. Dearden (1969) afirmou que praticamente todas as organizações, nos EUA, com administração descentralizada, estavam utilizando a mencionada ferramenta na época e alertou para a "miopia" que seu uso indiscriminado poderia gerar. Um exemplo citado é o da aquisição de um ativo de alto risco de obsolescência, que, segundo o método, deverá gerar o mesmo retorno que a aquisição de um de baixo risco. Assim, segundo a Fórmula DuPont, um equipamento eletrônico (alto risco de obsolescência) deve gerar o mesmo retorno sobre o investimento que um imóvel (baixo risco de obsolescência).

A idéia por trás da busca da maximização do ROI é coerente com a teoria do Mercado de Capitais. Ross, Westerfield e Jaffe (1995) explicam que, segundo essa teoria, o valor de mercado de uma empresa aumenta sempre que investir em projetos ou ativos de ROI superior ao seu custo ponderado de obtenção do capital (WACC) ou realizar desinvestimentos de projetos ou ativos com ROI inferior ao WACC ${ }^{5}$.

Outros mecanismos semelhantes à fórmula DuPont e com foco essencialmente no acionista, surgiram posteriormente nos EUA. No início da década de 1990, por exemplo, Stewart III (1991) propôs o Economic Value Added (EVA) como instrumento de gestão e controle organizacional. Segundo esse autor, para que uma empresa tenha melhor eficácia, a remuneração variável paga aos executivos e funcionários deveria ser atrelada ao indicador de valor agregado, cuja fórmula se traduz em: EVA $=$ [(ROI - WACC $) \times$ Capital Investido $]$.

Stewart III (1991), também, teria se baseado na teoria do Mercado de Capitais, pois afirma que "... a tarefa mais importante dos principais gestores da organização deve ser maximizar o valor de mercado da organização (...) um maior valor de mercado recompensa os acionistas, que são, afinal de contas, os verdadeiros donos do negócio" (STEWART III, 1991, p.1). O autor, talvez, deveria ter considerado que a busca pela maximização apenas de indicadores financeiros pudesse estimular a tomada de decisão orientada ao curto-prazo, que nem sempre são sustentáveis no médio e longo-prazo.

Em meados da década de 1990, surgiu outro instrumento de gestão e controle muito semelhante ao EVA: o VBM (Value-Based Management), criada por Copeland, Koller e Murrin (1995). O principal indicador do VBM, é o EP - Economic Profit (lucro econômico em português), que é praticamente idêntico à fórmula do EVA. O EP = [(ROIC - WACC) $x$ Capital Investido]. Apesar da semelhança, há diferença na nomenclatura de um dos componentes, pois, ao invés de utilizar o termo ROI para identificar o retorno sobre os investimentos, os autores do VBM o denominam de ROIC (Return On Invested Capital). Além disso, destaque-se o fato de o VBM ser desdobrado em uma árvore de indicadores matematicamente relacionados entre si, ao passo que essa característica não é tratada no EVA. Cabe ressaltar que esse desdobramento em árvore é praticamente idêntico ao modelo criado pela DuPont no início do século XX6.

No VBM, assim como no caso do EVA e da Fórmula DuPont, o foco no acionista também se faz presente,

\footnotetext{
1 EUA, Reino Unido, Canadá, e Austrália.

2 França, Itália, Espanha, e Bélgica.

3 Alemanha, Holanda, Suíça, Suécia, Áustria, Dinamarca, Noruega, e Finlândia.

4 Ver artigo de Dearden (1969).

5 WACC - Weighted Average Capital Cost, ou custo ponderado de capital em português. O custo ponderado de capital pondera o custo da dívida com o custo do capital próprio.

6 O desdobramento de indicadores em árvore, proposto pela DuPont pode ser verificado em Dearden (1969).
} 
uma vez que o autor afirma que “... a maximização do valor do acionista é, ou deveria ser, o maior objetivo de todas as organizações" (COPELAND; KOLLER; MURRIN, 1995, p.3).

A disseminação de instrumentos tais como a Fórmula DuPont, o EVA, e o VBM evidencia um certo culto à maximização do valor ao acionista existente na cultura norteamericana, uma vez que não se observou a mesma tendência em autores investigados de outros países. Essa visão é corroborada pelos próprios autores do VBM, Copeland, Koller e Murrin (1995), que afirmam que existe essa diferença cultural entre EUA, de um lado, e Europa e Japão, do outro. Além disso, conforme visto, Weimer e Pape (1999) apontam que os EUA são o país com o maior mercado de capitais.

Nesse contexto de críticas aos mecanismos de avaliação e monitoramento de desempenho econômico e de gestores, baseados exclusivamente em métricas financeiras, é que surgiu o Balanced Scorecard (BSC). Os autores Robert Kaplan e David Norton partiram da premissa de que a gestão baseada exclusivamente em indicadores financeiros, como no caso do EVA e VBM, estaria levando as organizações à miopia pelo excessivo foco no curto-prazo. Como conseqüência disso, gestores com remuneração variável atrelada unicamente a indicadores financeiros e valor acionário podem buscar a não investir (ou desinvestir) em projetos de pesquisa promissores, a fim de melhorar a lucratividade divulgada na publicação das demonstrações contábeis trimestrais de uma corporação (KAPLAN; NORTON, 2000).

Buscando prover solução aos problemas de miopia, como conseqüência do foco no curto-prazo, os autores do BSC propuseram integrar indicadores financeiros com indicadores não-financeiros. Isso proporcionaria um equilíbrio entre ambos os tipos, ao invés de concentrar todo o foco dos gestores nos indicadores de natureza financeira. Kaplan e Norton (1996) salientam que esse equilíbrio é importante, pois os indicadores não-financeiros são mais voltados ao longo-prazo, ao passo que os indicadores financeiros são mais voltados ao curto-prazo.

Segundo os autores do BSC, tanto o grupo de indicadores não-financeiros, quanto os financeiros tradicionais devem partir do foco no longo-prazo para, posteriormente, desdobrarem metas de curto-prazo. De acordo com Kaplan e Norton (1996), os principais executivos devem estabelecer metas com horizonte de três a cinco ano para direcionamento de uma organização, aliado a uma estratégia que suporte os objetivos desejados. A partir desse horizonte de longo-prazo, metas de curto-prazo (12 meses) devem ser estabelecidas.

Outro instrumento de gestão com horizonte no longoprazo, encontrado na literatura especializada, é o Planejamento Estratégico, o qual, segundo Mintzberg (1994), teria surgido em meados dos anos 60. De acordo com o entendimento de Ackoff (1980), o planejamento é um processo que se destina a produzir um ou mais estados futuros planejados e que não ocorrerão a menos que alguma coisa seja feita, voltando-se tal processo tanto para a prevenção de ações incorretas quanto para a redução da freqüência dos fracassos da empresa ao se explorar a oportunidade.

A maior semelhança entre o Planejamento Estratégico tradicional, mencionado por Mintzberg (1994), e o BSC encontra-se no fato de que ambos aspiram a estabelecer diretrizes de longo-prazo as quais devem ser seguidas de ações que suportem o alcance das metas desejadas. Dessa forma, ambos os instrumentos de gestão visam a impulsionar a organização na direção almejada por seus dirigentes. Em contrapartida, o equilíbrio entre metas financeiras e não-financeiras é um assunto tratado de forma explícita somente pelo BSC.

Desde seu surgimento, o BSC tem sido alvo de adesões e críticas. Lawson, Stratton e Hatch (2003), por exemplo, apontam benefícios ligados ao equilíbrio entre indicadores financeiros e não-financeiros verificados com a implementação do BSC. Otley (1999), por outro lado, comenta que o BSC continua, predominantemente, direcionado ao acionista e acredita que isso ocorre em função do ambiente cultural norte-americano, país onde o instrumento foi criado.

Verifica-se, assim, que o BSC surgiu com o propósito de chamar a atenção para o desempenho não-financeiro, justamente em um país com o maior mercado de capitais e com uma cultura fortemente voltada ao acionista, como os EUA. Otley (1999) corrobora, ao afirmar que o instrumento busca solucionar os problemas causados pelo excessivo foco nos indicadores financeiros que ocorrem no ambiente organizacional de empresas abertas. Ainda segundo o autor, o foco excessivo na divulgação de demonstrações contábeis por empresas abertas seria uma conseqüência do foco excessivo no acionista, característica marcante da cultura norte-americana.

A questão de pesquisa surge a partir de indícios disponíveis na literatura científica, indicando que o BSC pode estar associado às características culturais das empresas abertas. Assim, o problema sobre o qual este trabalho está pautado é: $\mathbf{O}$ tipo de sociedade de uma organização, aberta ou fechada, pode ser um fator que explique a melhor aderência da empresa ao Balanced Scorecard?

A fim de atender aos objetivos propostos, o presente estudo realizou uma análise comparativa entre empresas abertas e fechadas, com o intuito de analisar as diferenças nas suas características, verificando a aderência ao BSC, comparada à aderência aos instrumentos de gestão EVA / VBM e Planejamento Estratégico. 


\section{REFERENCIAL TEÓRICO}

\subsection{O BSC}

O primeiro artigo referente ao BSC foi publicado, em 1992, por Kaplan e Norton. Na época, os conceitos desse instrumento eram mais rudimentares que os atuais. Nesse artigo, os autores propuseram agrupar os indicadores de desempenho em quatro perspectivas distintas, quais sejam: (a) Financeira, (b) Clientes, (c) Processos Internos e (d) Aprendizado e Crescimento.

Com a publicação do primeiro livro, em 1996, os autores introduziram o conceito de relação de causa e efeito. Os autores explicam que as relações de causa e efeito são relações de hipótese do tipo "se-então", por exemplo: se os funcionários estiverem mais bem treinados, então nossos clientes ficarão mais satisfeitos (KAPLAN; NORTON, 1996).

Nesse livro, os autores afirmam que os indicadores de desempenho devem estar alinhados à estratégia. O livro, contudo, não torna claro se as relações de causa e efeito se aplicam apenas a objetivos estratégicos (exemplo: "meIhorar satisfação de clientes"), ou é aplicado a indicadores de desempenho também (exemplo: "índice de satisfação de clientes"). A afirmativa baseia-se no fato de que as mencionadas relações são encontradas tanto para objetivos estratégicos (KAPLAN; NORTON, 1996, p. 159), como para indicadores de desempenho (p. 167).

O conceito de Mapa Estratégico surgiu apenas com a publicação do segundo livro.

\section{Mapas Estratégicos}

Os Mapas Estratégicos devem descrever a estratégia da organização através de relações de causa e efeito entre Objetivos Estratégicos, criando-se, assim, relações baseadas em hipóteses. Por exemplo, "se melhorarmos nosso tempo de reabastecimento no solo, então reduziremos nossos custos operacionais". Assim o Objetivo Estratégico "Reduzir tempo de reabastecimento no solo", seria a causa do objetivo "Reduzir custos operacionais". Um bom Mapa Estratégico deve descrever o processo de transformar ativos intangíveis em resultados financeiros tangíveis (KAPLAN; NORTON, 2000).

Assim, a principal diferença entre o scorecard de 1996 e o Mapa Estratégico de 2000 é que o mencionado mapa deveria partir do objetivo estratégico supremo (atender às necessidades dos acionistas), sendo desencadeado em outros objetivos estratégicos. Logo, os indicadores de desempenho não são demonstrados no referido mapa, mas são associados aos objetivos estratégicos em tabelas à parte, sendo que cada objetivo pode ter um ou mais indicadores (KAPLAN; NORTON, 2000).

\section{Foco no acionista}

No início do segundo livro, os autores argumentam que os sistemas de medição de performance tradicionais eram demasiadamente focados na área financeira e tal foco conduziria a organização à miopia na visão de seus negó- cios, o que a levaria a tomar decisões voltadas apenas aos aspectos financeiros de curto-prazo. Os aspectos não-financeiros, segundo os autores, associados à sustentação em longo-prazo e criação de valor para o acionista ficavam, assim, prejudicados (KAPLAN; NORTON, 2000, p.3).

Os autores continuam sua argumentação sobre a importância da área financeira mais adiante no segundo livro. Segundo os idealizadores do BSC, a modelagem do Mapa Estratégico deve partir do objetivo máximo da organização que é a geração de valor para o acionista. Kaplan e Norton (2000, p.83) chegam a afirmar que "a criação de valor para o acionista deveria ser o resultado final de qualquer estratégia organizacional" (tradução do autor).

Kaplan e Norton (2000) afirmam que uma organização deve escolher um objetivo dominante como indicador de sucesso de longo-prazo. Como objetivo dominante, os autores sugerem o uso de indicadores de maximização de valor de mercado para o acionista, tais como o ROI da Fórmula DuPont, o EVA, ou o fluxo de caixa descontado.

Os comentários feitos por Kaplan e Norton (2000) dão indícios de que o foco do BSC é voltado ao atendimento das expectativas dos acionistas. Esse assunto será discutido com maior profundidade na Análise de Dados, uma vez que faz parte do objetivo central deste estudo.

\section{Estudos Favoráveis e Desfavoráveis ao BSC}

A seguir, serão apresentados estudos, direta ou indiretamente, relacionados ao BSC que visam contribuir para um melhor entendimento do instrumento estudado. Os estudos apresentam aspectos, ora positivos, ora negativos com relação ao instrumento.

a) Banker, Potter e Srinivasan (2000): Os pesquisadores buscaram verificar a relação entre indicadores não-financeiros e performance financeira. Os dados indicaram que há correlação entre satisfação de clientes, faturamento e lucro. O intervalo de tempo entre a melhoria no índice de satisfação do cliente e resultado financeiro foi de seis meses, em média. Dessa forma, foi verificado que, quando a rede hoteleira passou o foco de sua remuneração variável apenas dos indicadores financeiros para indicadores financeiros e não-financeiros, houve melhoria no desempenho organizacional. Isso sugere que o uso de indicadores não-financeiros de fato contribui para o desempenho organizacional, conforme preconizado por Kaplan e Norton.

b) Davis e Albright (2004): O estudo buscou investigar a capacidade de o BSC incrementar a performance financeira em uma organização. Foi analisado se o desempenho pós-implementação é significativamente superior a um ambiente similar em que o instrumento não foi implementado. Os pesquisadores verificaram que a unidade de negócios na qual o BSC foi implementado possuía desempenho financeiro superior à unidade de negócios que não 
havia implementado o BSC. O estudo não torna claro, entretanto, se tais benefícios ocorreram em função da aplicação do BSC, ou simplesmente devido ao emprego de indicadores não-financeiros. Os autores justificam sua pesquisa, afirmando que, apesar de já haver um bom número de estudos sobre o assunto, poucos buscaram investigar a capacidade de o BSC incrementar o desempenho financeiro de uma organização.

c) Malina e Selto (2001): O estudo buscou verificar a eficácia do BSC na comunicação e alinhamento estratégico, na motivação e nos resultados. A pesquisa concluiu que o BSC estava obtendo êxito em comunicar e alinhar a estratégia organizacional, e os gerentes estavam tomando decisões considerando os indicadores do instrumento gerencial. Os pesquisadores encontraram, entretanto, problemas na subjetividade da aferição de determinados indicadores, na implementação unidirecional do BSC (de cima para baixo) e no uso de benchmarks inapropriados. Esses problemas foram apontados pelos gerentes como causa de conflitos e tensões, gerando sentimento de ineficácia. Há de se considerar, também, o espaço relativamente curto de tempo desde o início da implementação do BSC. Considera-se a possibilidade de surgimento de outros problemas com o decorrer do tempo.

d) Ittner, Larcker e Randall (2003): Os pesquisadores investigaram a relação entre o uso de um amplo leque de indicadores financeiros e não-financeiros, e desempenho organizacional. O estudo também buscou verificar se o uso do BSC, do EVA ou do alinhamento de indicadores à estratégia acarretava maior desempenho organizacional. Os resultados indicaram correlação positiva entre diversidade de indicadores financeiros e, principalmente, indicadores não-financeiros, com performance organizacional. A referida correlação acentua-se nos casos em que não houve mudanças significativas no sistema de medição de performance nos últimos três anos. Em contraposição, o estudo encontrou evidências fracas de correlação entre sistemas de gestão do desempenho, tais como Balanced Scorecard, EVA, VBM e performance organizacional.

e) Norreklit (2000): O BSC foi analisado sob dois diferentes ângulos: (i) validade da relação de causaefeito proposta e (ii) habilidade do instrumento em alinhar a estratégia planejada à estratégia realizada. Com relação à validade da relação de causa - efeito proposta, o estudo apresenta dois problemas: (i.i) a dimensão tempo não é evidenciada na relação e (i.ii) as relações causa-efeito são muitas vezes questionáveis, quando um incremento em um indicador causal não causar a repercussão esperada no indicador de efeito. Com relação à habilidade do instrumento em alinhar a estratégia planejada à estratégia realizada, outros dois problemas são apresentados: (ii.i) problemas com relação a diversas perspectivas que não são tratadas (fornecedores, governo, social etc.) e (ii.ii) problemas apontados com relação à implementação estilo top-down, inerente ao BSC, segundo a autora.

f) Pessanha e Prochnik (2004): Foi realizado um estudo com três empresas brasileiras que haviam implementado o BSC recentemente. A partir de 18 questões sobre o tema, os autores verificaram que os três casos apresentavam problemas em relação ao modelo proposto por Kaplan e Norton. Os principais problemas apontados são: (i) Pouca ou nenhuma participação dos escalóes inferiores na modelagem e implantação do BSC; (ii) Medidas financeiras mais apreciadas pela alta administração, que não dá muita importância aos indicadores não-financeiros; (iii) Foco no curto-prazo, sendo que o processo orçamentário era voltado ao acionista e ênfase inferior à necessária era dada ao planejamento estratégico.

\subsection{O EVA e o VBM}

O EVA e o VBM, apesar de serem dois instrumentos de gestão distintos, são muito similares. Ambos possuem várias características em comum, como por exemplo (a) foco na criação de valor para o acionista de forma semelhante à Fórmula DuPont; (b) indicadores de criação de valor de ambos idênticos; (c) ambos tratam de forma superficial a estratégia organizacional explícita. Pressupõem que atrelar o EVA ou o EP (indicador de agregação de valor do VBM) a incentivos financeiros seja suficiente para que os executivos e funcionários se sintam naturalmente motivados a executar as iniciativas que mais agregam valor ao acionista. Assim, as melhores decisões, bem como a melhor estratégia para a organização seria executada de forma intuitiva, na busca pela maximização do EVA ou EP.

A bibliografia especializada indica que uma das diferenças mais significativas entre o EVA e o VBM se encontra na proposta de Copeland, Koller e Murrin (1995) de desmembrar o ROIC em uma árvore de indicadores subordinados, como já mencionado. Esses indicadores subordinados ao ROIC deveriam ser utilizados como métricas das unidades de negócios, descendo até o nível departamental. Assim, toda a organização estaria mobilizada para o incremento contínuo do ROIC e, dessa forma, à agregação contínua de valor (COPELAND; KOLLER; MURRIN, 1995).

Considerando que tanto o EVA quanto o VBM são focados basicamente em indicadores financeiros, percebe-se que o BSC se propõe a preencher a lacuna da gestão dos indicadores não-financeiros, deixada por tais instrumentos de gestão.

\subsection{O Planejamento Estratégico}

Planejamento Estratégico é um instrumento de gestão que consolida um método estruturado de tomada de decisões que envolvam uma determinada situação futura e desejada, cujo principal objetivo é se antecipar o que e como fazer. As ações mais relevantes no cotidiano de uma 
empresa refletem, normalmente, algum tipo de decisão tomada no passado.

O entendimento de Ackoff (1980) para o planejamento é que se trata de um processo destinado a produzir um ou mais estados futuros, sendo necessária uma ação voluntária para a obtenção do resultado desejado. A estruturação do planejamento empresarial visa tanto a prevenir de ações incorretas quanto a reduzir a freqüência dos fracassos da empresa ao se explorar a oportunidade.

O planejamento é necessário quando a consecução do estado futuro que se deseje envolve um conjunto de decisões interdependentes, isto é, um sistema de decisões qualitativas no qual algumas ações podem ser complexas e outras mais simples, sendo, entretanto, todas elas interdependentes. Essa característica é uma das principais complexidades associadas à elaboração do Planejamento Estratégico, pois isso requer um ajustamento perfeito dessa cadeia sistêmica de decisões e a avaliação de suas conseqüências.

Simon (1960) corrobora a importância sistêmica do Planejamento Estratégico quando constata que o conceito inerente envolve a noção de hierarquia de decisões em que cada passo no sentido descendente consiste na implementação dos objetivos estabelecidos no plano imediatamente anterior.

Dessa forma, a elaboração de planejamentos estratégicos eficazes é uma tarefa que, além de dispendiosa, não é simples. A turbulência e dinamismo ambiental, associados a outros fatores intrínsecos a uma organização, são variá- veis que desafiam a capacidade, criatividade e experiência dos gestores para controlá-los. A elaboração do planejamento requer sabedoria, sem a qual os seus resultados práticos tendem a ser insípidos, com benefícios que não superam os custos de sua realização.

A sabedoria, de acordo com Ackoff (1980), é a capacidade de prever as conseqüências, a longo prazo, de decisões tomadas hoje. É a disposição de se sacrificarem os ganhos a curto prazo em favor de benefícios e estabilidade a longo prazo. É a habilidade de controlar o que, aparentemente, é incontrolável.

Além de envolver decisões que têm um foco no médio e longo prazo, a escolha da estratégia tem uma característica essencialmente qualitativa e sua quantificação não é tarefa fácil, podendo constituir-se em dificuldades que podem levar ao insucesso a sua implementação, considerando-se o caráter sistêmico do Planejamento Estratégico. É justamente nesse aspecto que se apegam os idealizadores do $\mathrm{BSC}$, que propõem ser esse instrumento um facilitador para a comunicação da estratégia (KAPLAN; NORTON, 1996). Minimiza-se, dessa forma, com tal instrumento de gestão, os riscos de que as decisões tomadas sistemicamente pela alta administração da empresa não produzam os resultados por ela desejados. Além disso, diferentemente do Planejamento Estratégico, o instrumento criado por Kaplan e Norton tem a intenção explícita de "equilibrar" a ênfase dada aos aspectos financeiros com os não-financeiros na elaboração da estratégia.

\section{MÉTODO DO ESTUDO}

O universo deste estudo compreende as empresas da região Sul e Sudeste do Brasil. As demais regiões não foram abordadas, uma vez que o PIB dessas duas regiões representa $73,8 \%$ do PIB brasileiro, segundo o IBGE. Assim, julgou-se que essas duas regiões seriam suficientes para atingir os objetivos deste estudo. Definiu-se, de forma arbitrária, que empresas com faturamento abaixo de $\mathrm{R} \$ 10$ milhões não fariam parte do universo deste estudo. Considerou-se que empresas com faturamento inferior a essa cifra possam, talvez, não apresentar estrutura suficiente que permita a análise de seus instrumentos de gestão do desempenho.

A partir dos cadastros da FIESP, SEBRAE, Revista Amanhã 500 e FEDERASUL, foi selecionada uma amostra nãoprobabilística de 350 empresas das duas regiões supracitadas. Com a amostra em mãos, contatou-se as empresas por telefone ${ }^{7}$, explicando a natureza da pesquisa. Ao concordar em participar da pesquisa, enviou-se um e-mail instruindo o respondente a entrar em um site ${ }^{8}$, em que era possível preencher o questionário. Passava-se ao respondente, também, um login e uma senha para acesso, a fim de tornar possível a sua identificação.

Das 350 empresas contatadas, 79 responderam ao questionário. Contataram-se as empresas sempre que houve necessidade de verificar a coerência das respostas, uma vez que há um encadeamento lógico entre as questões. Dois questionários foram desclassificados, por inconsistência verificada nas respostas, apesar de o contato com essas empresas ter sido feito. Assim, a amostra final deste estudo consistiu em 77 empresas: 34 abertas e 43 fechadas. Quanto ao porte, 33 empresas têm faturamento anual entre $\mathrm{R} \$ 10$ milhões e $\mathrm{R} \$ 150$ milhões e 44 têm faturamento anual superior a $\mathrm{R} \$ 150$ milhões.

Para aplicação dos testes estatísticos, utilizou-se o software SPSS - Statistical Package for Social Sciences for Windows, na versão 13.0, de onde se obtiveram as seguintes informações: (a) distribuições de freqüência, (b) testes qui-quadrado e (c) testes Phi e Cramér's V9.

\footnotetext{
7 Buscou-se sempre fazer contato com algum dos seguintes gestores: com o executivo principal da empresa, com o Controller, com o Gerente da Contabilidade, ou com o executivo financeiro da empresa. Em todos os casos, o nível hierárquico foi de gerência ou diretoria.

8 O endereço do site não é divulgado a fim de se evitar a possibilidade de identificação dos autores da pesquisa.

9 Tradicionalmente, resultados próximos a 0,10, 0,30, e 0,50, são considerados de intensidade "fraca", "moderada" e "elevada", respectivamente.
} 
Fonseca e Martins (1996) afirmam, ainda, que os níveis de risco tradicionalmente utilizados são de 1\%, 5\% e 10\%. Verificou-se, na literatura consultada, que o nível de risco mais comumente utilizado é de $5 \%$. Assim, para efeitos deste estudo, utilizou-se esse nível de risco ( $\alpha=5 \%)$.

Guimarães e Cabral (1998) afirmam que, para uso do teste qui-quadrado, a amostra deve ser igual ou superior a 30, e a freqüência esperada em cada célula não deve ser inferior a 5. Esses autores esclarecem que, se essa última condição não prevalecer, se aceitam, com moderada confiança, até $20 \%$ das células com valores esperados inferiores a 5, porém nenhum deve ser inferior a 1. Quando isso não se verificar, recomenda-se agregar classificações adjacentes de forma a obter novas categorias que satisfaçam a condição. Assim, para efeitos deste estudo, sempre que foi necessário agregar classes adjacentes em testes qui-quadrado, recorreu-se a notas de fim de texto para explicar como foi feita a mencionada agregação.

A extrapolação dos resultados encontrados pode ser feita, uma vez que a freqüência tanto das empresas abertas, quanto das fechadas é superior a 30. Recomenda-se, entretanto, cautela na generalização dos resultados, considerando a possibilidade da existência de viés na pesquisa.

\section{ANÁLISE DOS DADOS}

\subsection{Análise do comportamento das organizações diante do uso de indicadores}

Esta análise visa identificar como as organizações se comportam ante o uso de indicadores de desempenho para a tomada de decisão. Os dados serão analisados de acordo com a seguinte estrutura: (a) descrição da questão; (b) apresentação dos dados das empresas abertas e fechadas; (c) análise dos dados encontrados.

A análise aborda a forma como as organizações tratam oito diferentes fatores, a saber: (1) Financeiro; (2) Mercado; (3) Processos Internos; (4) Recursos Humanos; (5) Relação com o Governo; (6) Relação com a Sociedade; (7) Relação com Fornecedores; (8) Relação com o Meio-Ambiente. Os quatro primeiros fatores estão relacionados às quatro perspectivas do BSC, criadas por seus autores. Os quatro últimos fatores, de forma proposital, não se enquadram em nenhuma das quatro perspectivas do BSC.

Questão 1: Qual o nível de importância de cada fator apontado abaixo para o processo de tomada de decisão, segundo aquilo que de fato ocorre na sua empresa?

Pela análise da distribuição de freqüência verificada na Tabela $1 \boldsymbol{O}$, percebe-se que, de forma geral, as empresas abertas atribuem maior importância ao fator financeiro do que aos demais fatores, uma vez que $76,5 \%$ desse grupo de empresas atribuíram grau de importância "muito elevado" ao fator financeiro. Para esse grau de importância, verifica-se que os demais fatores se encontram entre 5,9\% e 47,1\%. Segundo Kaplan e Norton, esse "desequilíbrio" não está adequado ao atual ambiente de negócios. Conforme mencionado no referencial teórico, os mentores do BSC apontam que o atual ambiente de negócios exige maior equilíbrio entre o fator financeiro e os demais fatores.

A maior importância atribuída ao fator financeiro pelas empresas abertas ocorre, possivelmente, em decorrência do fato de que os gestores desse grupo de empresas sofrem pressões contínuas por parte dos acionistas para apresentarem demonstrações contábeis com índices almejados por eles. Há de se considerar o impacto que a publicação trimestral das demonstrações contábeis tem no preço das ações das empresas abertas na Bolsa de Valores, bem como a pressão dos acionistas para que o valor de suas ações atinja o maior nível possível.

Por outro lado, a análise da distribuição de freqüência na Tabela $2 \oslash$ revela que as empresas fechadas apresentam maior equilíbrio entre o fator financeiro e os demais fatores. Constata-se que $48,8 \%$ desse grupo de empresas atribuíram grau de importância "muito elevado" ao fator financeiro, e, para esse grau de importância, verifica-se que os demais fatores se encontram entre 11,6\% e 46,5\%. Assim, esse grupo de empresas estaria mais enquadrado

Tabela 1 Grau de importância atribuído pelas empresas abertas a cada um dos oito fatores estudados para o processo de tomada de decisão

\begin{tabular}{|c|c|c|c|c|c|c|c|c|}
\hline & Financeiro & Mercado & $\begin{array}{l}\text { Processos } \\
\text { Internos }\end{array}$ & $\mathbf{R H}$ & $\begin{array}{c}\text { Relacão c/ } \\
\text { Governo }\end{array}$ & $\begin{array}{l}\text { Relação c/ } \\
\text { Sociedade }\end{array}$ & $\begin{array}{l}\text { Relação } \\
\text { c/ Forne- } \\
\text { cedores }\end{array}$ & $\begin{array}{c}\text { Rel. c/ } \\
\text { Meio- } \\
\text { Ambiente }\end{array}$ \\
\hline Nenhum & $0,0 \%$ & $2,9 \%$ & $0,0 \%$ & $2,9 \%$ & $2,9 \%$ & $8,8 \%$ & $0,0 \%$ & $2,9 \%$ \\
\hline Pouco & $0,0 \%$ & $5,9 \%$ & $2,9 \%$ & $14,7 \%$ & $20,6 \%$ & $14,7 \%$ & $0,0 \%$ & $5,9 \%$ \\
\hline Intermediário & $8,8 \%$ & $11,8 \%$ & $11,8 \%$ & $38,2 \%$ & $44,1 \%$ & $38,2 \%$ & $17,6 \%$ & $17,6 \%$ \\
\hline Elevado & $14,7 \%$ & $32,4 \%$ & $41,2 \%$ & $38,2 \%$ & $26,5 \%$ & $29,4 \%$ & $55,9 \%$ & $29,4 \%$ \\
\hline $\begin{array}{l}\text { Muito } \\
\text { Elevado }\end{array}$ & $76,5 \%$ & $47,1 \%$ & $44,1 \%$ & $5,9 \%$ & $5,9 \%$ & $8,8 \%$ & $26,5 \%$ & $44,1 \%$ \\
\hline
\end{tabular}


Tabela 2 Grau de importância atribuído pelas empresas fechadas a cada um dos oito fatores estudados para o processo de tomada de decisão

\begin{tabular}{|c|c|c|c|c|c|c|c|c|}
\hline & Financeiro & Mercado & $\begin{array}{l}\text { Processos } \\
\text { Internos }\end{array}$ & $\mathbf{R H}$ & $\begin{array}{c}\text { Relacão c/ } \\
\text { Governo }\end{array}$ & $\begin{array}{l}\text { Relação c/ } \\
\text { Sociedade }\end{array}$ & $\begin{array}{l}\text { Relação } \\
\text { c/ Forne- } \\
\text { cedores }\end{array}$ & $\begin{array}{c}\text { Rel. c/ } \\
\text { Meio- } \\
\text { Ambiente }\end{array}$ \\
\hline Nenhum & $0,0 \%$ & $0,0 \%$ & $0,0 \%$ & $0,0 \%$ & $14,0 \%$ & $0,0 \%$ & $2,3 \%$ & $4,7 \%$ \\
\hline Pouco & $0,0 \%$ & $7,0 \%$ & $9,3 \%$ & $16,3 \%$ & $23,3 \%$ & $20,9 \%$ & $4,7 \%$ & $14,0 \%$ \\
\hline Intermediário & $14,0 \%$ & $18,6 \%$ & $25,6 \%$ & $32,6 \%$ & $32,6 \%$ & $27,9 \%$ & $16,3 \%$ & $14,0 \%$ \\
\hline Elevado & $37,2 \%$ & $27,9 \%$ & $39,5 \%$ & $37,2 \%$ & $18,6 \%$ & $32,6 \%$ & $46,5 \%$ & $39,5 \%$ \\
\hline $\begin{array}{l}\text { Muito } \\
\text { Elevado }\end{array}$ & $48,8 \%$ & $46,5 \%$ & $25,6 \%$ & $14,0 \%$ & $11,6 \%$ & $18,6 \%$ & $30,2 \%$ & $27,9 \%$ \\
\hline
\end{tabular}

dentro do que os autores do BSC consideram como uma necessidade para o atual ambiente de negócios, ao comparar com as empresas abertas.

O teste qui-quadrado confirma a associação encontrada entre o tipo de sociedade (aberta ou fechada) e a importância atribuída ao fator financeiro, cujo resultado é de $0,014<\alpha=0,05^{10}$. A força dessa associação pode ser classificada como intermediária, uma vez que o resultado do teste Phi é próximo a 0,30 .

Infere-se que há duas possibilidades para o maior equilíbrio verificado entre os oito fatores em análise nas empresas fechadas. Uma possibilidade seria em função de uma cultura organizacional mais propensa a que o referido equilíbrio ocorra. Outra seria a de que as empresas fechadas utilizam mais o BSC do que as empresas abertas. Ver-se-á se essa segunda possibilidade ocorre de fato mais adiante, na continuação da Análise dos Dados. Nesse caso, se confirmada, poder-se-ia concluir que o uso do BSC nas empresas fechadas proporciona maior equilíbrio entre o fator financeiro e os demais fatores.

As características do BSC, voltadas às empresas abertas, começam a fazer sentido diante da distribuição de freqüência da Tabela 1 e do resultado dos testes qui-quadrado, uma vez que segundo seus criadores, o BSC é um instrumento de gestão do desempenho voltado a estabelecer o equilíbrio entre o fator financeiro com os não-financeiros. Segundo Otley (1999), o BSC visa solucionar os problemas causados pelo excessivo foco nos indicadores financeiros dentro do ambiente organizacional de empresas abertas. $O$ foco excessivo na divulgação de demonstrações contábeis por parte das empresas abertas seria, assim, uma conseqüência do foco excessivo no acionista.

Questão 2: Na sua empresa, qual o nível de implementação de análises quantitativas e indicadores de desempenho para cada um dos fatores abaixo?

A análise das distribuições de freqüência na Tabela 30 evidencia que o fator financeiro apresenta o maior nível de implementação de análises quantitativas e indicadores de desempenho nas empresas abertas. Verifica-se que $82,4 \%$ das empresas informaram nível de implementação "muito elevado" ou "elevado" ao referido fator. Essa constatação faz sentido a partir da verificação de que o mencionado fator é considerado o mais importante por esse grupo de empresas.

Já pela análise da distribuição de freqüência da Tabela 40 , percebe-se que o nível de implementação dos indicadores de desempenho de natureza financeira nas empresas fechadas é inferior ao das empresas abertas. Cerca de 53\% das empresas fechadas informaram nível de implementação "muito elevado" ou "elevado" para o mencionado grupo de indicadores.

Novamente, é confirmada a elevada importância que as empresas abertas atribuem ao fator financeiro. Os da-

Tabela 3 Nível de implementação de análises quantitativas e indicadores de desempenho, considerando o ambiente das empresas abertas

\begin{tabular}{l|c|c|c|c|c|c|c|c} 
& Financeiro & Mercado & $\begin{array}{c}\text { Processos } \\
\text { Internos }\end{array}$ & RH & $\begin{array}{c}\text { Relacão c/ } \\
\text { Governo }\end{array}$ & $\begin{array}{c}\text { Relação cl } \\
\text { Sociedade }\end{array}$ & $\begin{array}{c}\text { Relação } \\
\text { c/ Forne- } \\
\text { cedores }\end{array}$ & $\begin{array}{c}\text { Rel. cl } \\
\text { Meio- } \\
\text { Ambiente }\end{array}$ \\
\hline Nenhum & $0,0 \%$ & $0,0 \%$ & $2,9 \%$ & $2,9 \%$ & $8,8 \%$ & $5,9 \%$ & $0,0 \%$ & $5,9 \%$ \\
\hline Pouco & $5,9 \%$ & $14,7 \%$ & $8,8 \%$ & $20,6 \%$ & $47,1 \%$ & $47,1 \%$ & $5,9 \%$ & $17,6 \%$ \\
\hline Intermediário & $11,8 \%$ & $17,6 \%$ & $17,6 \%$ & $35,3 \%$ & $23,5 \%$ & $20,6 \%$ & $35,3 \%$ & $35,3 \%$ \\
\hline Elevado & $50,0 \%$ & $47,1 \%$ & $44,1 \%$ & $41,2 \%$ & $11,8 \%$ & $20,6 \%$ & $44,1 \%$ & $17,6 \%$ \\
\hline $\begin{array}{l}\text { Muito } \\
\text { Elevado }\end{array}$ & $32,4 \%$ & $20,6 \%$ & $26,5 \%$ & $0,0 \%$ & $8,8 \%$ & $5,9 \%$ & $14,7 \%$ & $23,5 \%$
\end{tabular}


Tabela 4 Nível de implementação de análises quantitativas e indicadores de desempenho, considerando o ambiente das empresas fechadas

\begin{tabular}{|c|c|c|c|c|c|c|c|c|}
\hline & Financeiro & Mercado & $\begin{array}{l}\text { Processos } \\
\text { Internos }\end{array}$ & $\mathbf{R H}$ & $\begin{array}{c}\text { Relacão c/ } \\
\text { Governo }\end{array}$ & $\begin{array}{l}\text { Relação c/ } \\
\text { Sociedade }\end{array}$ & $\begin{array}{l}\text { Relação } \\
\text { c/ Forne- } \\
\text { cedores }\end{array}$ & $\begin{array}{c}\text { Rel. c/ } \\
\text { Meio- } \\
\text { Ambiente }\end{array}$ \\
\hline Nenhum & $0,0 \%$ & $0,0 \%$ & $0,0 \%$ & $0,0 \%$ & $20,9 \%$ & $11,6 \%$ & $2,3 \%$ & $14,0 \%$ \\
\hline Pouco & $9,3 \%$ & $18,6 \%$ & $14,0 \%$ & $20,9 \%$ & $32,6 \%$ & $30,2 \%$ & $23,3 \%$ & $20,9 \%$ \\
\hline Intermediário & $37,2 \%$ & $37,2 \%$ & $41,9 \%$ & $48,8 \%$ & $18,6 \%$ & $25,6 \%$ & $37,2 \%$ & $16,3 \%$ \\
\hline Elevado & $41,9 \%$ & $37,2 \%$ & $41,9 \%$ & $25,6 \%$ & $18,6 \%$ & $23,3 \%$ & $34,9 \%$ & $44,2 \%$ \\
\hline $\begin{array}{l}\text { Muito } \\
\text { Elevado }\end{array}$ & $11,6 \%$ & $7,0 \%$ & $2,3 \%$ & $4,7 \%$ & $9,3 \%$ & $9,3 \%$ & $2,3 \%$ & $4,7 \%$ \\
\hline
\end{tabular}

dos encontrados até o momento reforçam a idéia de que a cultura desse grupo de organizações é influenciada pela necessidade de evidenciar demonstrações contábeis a cada trimestre. Assim, deduz-se que a prioridade desse grupo de empresas possa ser o atendimento das expectativas de seus acionistas, ficando a importância dos demais fatores em segundo plano.

A associação entre o tipo de sociedade e o nível de implementação dos indicadores de natureza financeira pode ser confirmada pelo teste qui-quadrado, cujo resultado é de $0,012<\alpha=0,05^{11}$. Classifica-se o grau de força da associação como intermediário, uma vez que o resultado do teste Cramér's Vé próximo a 0,30.

\subsection{Uso do BSC como instrumento de gestão, ante o uso de outros instrumentos de gestão}

Kaplan e Norton (2000) relatam que o BSC proporciona: (a) alinhamento dos indicadores à estratégia; (b) comunicação da estratégia dentro da organização e (c) apoio na tomada de decisão. Ittner, Larcker e Randall (2003) argumentam que tanto o BSC, quanto ferramentas de valoração econômica, tais como o EVA e o VBM, contribuem para o alinhamento e a comunicação da estratégia, bem como no apoio à tomada de decisões. Reiterando o objetivo, este estudo visa a identificar como as organizações se comportam em relação ao uso do BSC (itens "a”, "b” e "c" acima) ante o uso de outros instrumentos, dentre os quais os principais são: (i) Planejamento Estratégico e (ii) EVA / VBM.

Além dos instrumentos supracitados, algumas questões comparam o BSC, também, com procedimentos, que não necessariamente estejam relacionados a algum instrumento de gestão específico, tais como: reuniões periódicas com funcionários; uso e análise de indicadores financeiros; uso e análise de indicadores não-financeiros. Em função disso, utilizou-se o termo "procedimento de gestão" no questionário, para se referir tanto aos instrumentos de gestão, como aos mencionados procedimentos.

A seguir, serão apresentadas três questões referentes aos itens "a", "b", e "c" supracitados, com as respectivas tabelas de freqüência logo abaixo. A análise interpretativa dos dados será feita logo após as três questões.

Questão 3: Quanto cada procedimento de gestão abaixo contribui para o alinhamento dos indicadores à estratégia, segundo aquilo que de fato ocorre na sua empresa? Vide Tabela $5 \boldsymbol{0}$.

Tabela 5 Contribuição de cada procedimento de gestão para alinhamento dos indicadores à estratégia

\begin{tabular}{l|c|c|c|c|c|c|c|c} 
& $\begin{array}{c}\text { Planejamento } \\
\text { Estratégico }\end{array}$ & BSC & $\begin{array}{c}\text { EVA/ } \\
\text { VBM }\end{array}$ & $\begin{array}{c}\text { Reuniões } \\
\text { Periódicas }\end{array}$ & $\begin{array}{c}\text { Planejamento } \\
\text { Estratégico }\end{array}$ & BSC & $\begin{array}{c}\text { EVA/ } \\
\text { VBM }\end{array}$ & $\begin{array}{c}\text { Reuniões } \\
\text { Periódicas }\end{array}$ \\
\hline $\begin{array}{l}\text { Tipo Socied. } \\
\text { Nenhum }\end{array}$ & $5,9 \%$ & $26,5 \%$ & $38,2 \%$ & $11,8 \%$ & $7,0 \%$ & $60,5 \%$ & $44,2 \%$ & $2,3 \%$ \\
\hline Pouco & $11,8 \%$ & $8,8 \%$ & $11,8 \%$ & $11,8 \%$ & $11,6 \%$ & $4,7 \%$ & $9,3 \%$ & $23,3 \%$ \\
\hline Intermediário & $29,4 \%$ & $29,4 \%$ & $11,8 \%$ & $20,6 \%$ & $32,6 \%$ & $20,9 \%$ & $30,2 \%$ & $20,9 \%$ \\
\hline Elevado & $26,5 \%$ & $17,6 \%$ & $26,5 \%$ & $44,1 \%$ & $34,9 \%$ & $9,3 \%$ & $11,6 \%$ & $41,9 \%$ \\
\hline $\begin{array}{l}\text { Muito } \\
\text { Elevado }\end{array}$ & $26,5 \%$ & $17,6 \%$ & $11,8 \%$ & $11,8 \%$ & $14,0 \%$ & $4,7 \%$ & $4,7 \%$ & $11,6 \%$ \\
\end{tabular}


Questão 4: Quanto cada procedimento de gestão abaixo contribui para a divulgação da estraté- gia, segundo aquilo que de fato ocorre na sua empresa? Vide Tabela 60.

Tabela 6 - Contribuição de cada procedimento de gestão para a divulgação da estratégia

\begin{tabular}{l|c|c|c|c|c|c|c|c|c} 
& $\begin{array}{c}\text { Planejamento } \\
\text { Estratégico }\end{array}$ & BSC & $\begin{array}{c}\text { EVA/ } \\
\text { VBM }\end{array}$ & $\begin{array}{c}\text { Reuniões } \\
\text { Periódicas }\end{array}$ & $\begin{array}{c}\text { Planejamento } \\
\text { Estratégico }\end{array}$ & BSC & $\begin{array}{c}\text { EVA/ } \\
\text { VBM }\end{array}$ & $\begin{array}{c}\text { Reuniões } \\
\text { Periódicas }\end{array}$ \\
\hline Tipo Socied. & \multicolumn{7}{|c|}{ Capital Aberto } \\
\hline Nenhum & $8,8 \%$ & $35,3 \%$ & $50,0 \%$ & $5,9 \%$ & $4,7 \%$ & $60,5 \%$ & $44,2 \%$ & $2,3 \%$ \\
\hline Pouco & $11,8 \%$ & $11,8 \%$ & $5,9 \%$ & $14,7 \%$ & $18,6 \%$ & $11,6 \%$ & $16,3 \%$ & $27,9 \%$ \\
\hline Intermediário & $29,4 \%$ & $20,6 \%$ & $8,8 \%$ & $20,6 \%$ & $16,3 \%$ & $16,3 \%$ & $23,3 \%$ & $18,6 \%$ \\
\hline Elevado & $38,2 \%$ & $17,6 \%$ & $23,5 \%$ & $44,1 \%$ & $39,5 \%$ & $7,0 \%$ & $11,6 \%$ & $37,2 \%$ \\
\hline $\begin{array}{l}\text { Muito } \\
\text { Elevado }\end{array}$ & $11,8 \%$ & $14,7 \%$ & $11,8 \%$ & $14,7 \%$ & $20,9 \%$ & $4,7 \%$ & $4,7 \%$ & $14,0 \%$ \\
\end{tabular}

Questão 5: Quanto cada procedimento de gestão abaixo contribui para a tomada de decisão, se- gundo aquilo que de fato ocorre na sua empresa? Vide Tabela 70

Tabela 7 - Contribuição de cada procedimento de gestão para a tomada de decisão ${ }^{12}$

\begin{tabular}{|c|c|c|c|c|c|}
\hline & BSC & $\begin{array}{l}\text { EVA/ } \\
\text { VBM }\end{array}$ & $\begin{array}{l}\text { Planejamento } \\
\text { Estratégico }\end{array}$ & $\begin{array}{l}\text { Uso } \\
\text { de IF }\end{array}$ & $\begin{array}{l}\text { Uso } \\
\text { de INF }\end{array}$ \\
\hline Tipo Socied. & \multicolumn{5}{|c|}{ Capital Aberto } \\
\hline Nenhum & $23,1 \%$ & $9,5 \%$ & $0,0 \%$ & $0,0 \%$ & $0,0 \%$ \\
\hline Pouco & $19,2 \%$ & $23,8 \%$ & $6,1 \%$ & $2,9 \%$ & $11,8 \%$ \\
\hline Intermediário & $15,4 \%$ & $9,5 \%$ & $30,3 \%$ & $14,7 \%$ & $20,6 \%$ \\
\hline Elevado & $30,8 \%$ & $33,3 \%$ & $30,3 \%$ & $32,4 \%$ & $52,9 \%$ \\
\hline \multirow[t]{2}{*}{ Muito Elevado } & $11,5 \%$ & $23,8 \%$ & $33,3 \%$ & $50,0 \%$ & $14,7 \%$ \\
\hline & BSC & $\begin{array}{l}\text { EVA/ } \\
\text { VBM }\end{array}$ & $\begin{array}{c}\text { Planejamento } \\
\text { Estratégico }\end{array}$ & $\begin{array}{l}\text { Uso } \\
\text { de IF }\end{array}$ & $\begin{array}{l}\text { Uso } \\
\text { de INF }\end{array}$ \\
\hline Tipo Socied. & \multicolumn{5}{|c|}{ Capital Fechado } \\
\hline Nenhum & $5,6 \%$ & $3,6 \%$ & $2,4 \%$ & $0,0 \%$ & $2,3 \%$ \\
\hline Pouco & $33,3 \%$ & $39,3 \%$ & $7,3 \%$ & $11,6 \%$ & $14,0 \%$ \\
\hline Intermediário & $22,2 \%$ & $25,0 \%$ & $22,0 \%$ & $16,3 \%$ & $32,6 \%$ \\
\hline Elevado & $22,2 \%$ & $21,4 \%$ & $46,3 \%$ & $32,6 \%$ & $34,9 \%$ \\
\hline Muito Elevado & $16,7 \%$ & $10,7 \%$ & $22,0 \%$ & $39,5 \%$ & $16,3 \%$ \\
\hline
\end{tabular}

As análises revelam que tanto as empresas abertas, como as fechadas utilizam predominantemente o Planejamento Estratégico, bem como indicadores de desempenho e reuniões periódicas para a gestão do seu desempenho.

Percebe-se que o BSC é mais utilizado pelas empresas abertas do que pelas empresas fechadas, ao se analisarem, conjuntamente, os graus de contribuição "muito elevado" e "elevado" para as questões 3,4 , e 5 . Os resultados de $35,2 \%, 32,3 \%$, e $42,3 \%$ foram encontrados para as empresas abertas, respectivamente; e resultados de $14,0 \%$, $11,7 \%, 38,9 \%$ para as empresas fechadas, respectivamen- te. Por outro lado, quando está sendo analisado o uso do Planejamento Estratégico, verifica-se que esse instrumento é mais utilizado pelas empresas fechadas, do que pelas empresas abertas. Nesse caso, foram encontrados resultados de $53,0 \%, 50,0 \%$, e $63,6 \%$ para as empresas abertas, respectivamente; e resultados de 48,9\%, 60,4\%, 68,3\% para as empresas fechadas, respectivamente.

Assim, os dados apresentados até o momento, sugerem que, de um modo geral, o uso do BSC está associado ao tipo de sociedade. Na verificação do teste qui-quadrado, considerou-se que a empresa não era usuária do BSC ao assinalar 
"nenhum" grau de contribuição para: o alinhamento dos indicadores à estratégia (questão 3), divulgação da estratégia (questão 4), e apoio na tomada de decisões (questão 5). Caso contrário, se a empresa assinalou no mínimo "pouco" grau de contribuição para qualquer uma das três questões abordadas, considerou-se que a empresa era usuária do BSC.

A Tabela $8 \mathbf{0}$, a seguir, demonstra a proporção de empresas que utilizam e que não utilizam o BSC, segundo 0 critério definido no parágrafo anterior. Da mesma forma, o Planejamento Estratégico é, também, apresentado com o intuito de comparar seu uso ao uso do BSC.

Percebe-se que cerca de $57 \%$ das empresas utilizam o BSC, seja de pouca, seja de muita intensidade. Por outro lado cerca de $43 \%$ das empresas não fazem uso do BSC em nenhum aspecto da sua gestão do desempenho. Já quanto ao Planejamento Estratégico, percebe-se que quase a totalidade das empresas utilizam esse instrumento de gestão, confirmando sua elevada aceitação nas organizações.

$\mathrm{O}$ teste qui-quadrado, cujo resultado foi de $0,002<$ $\alpha=0,05$, confirma mais uma vez que o uso do BSC está associado ao tipo de sociedade, corroborando o referencial teórico, bem como os resultados encontrados até o momento. A força dessa associação pode ser classificada como intermediária, uma vez que o resultado do teste Phi é próximo a 0,30.

\subsection{Análise dos alvos prioritários das empresas}

Acredita-se que as empresas abertas e fechadas teriam valores culturais diferenciados. Essas diferenças poderiam ser a causa da maior ênfase que as empresas abertas deram ao fator financeiro, conforme visto.

Buscou-se analisar as possíveis diferenças culturais entre empresas abertas e fechadas através da análise dos alvos prioritários das organizações. Assim, buscou-se identificar quais são os alvos prioritários das empresas, por tipo de sociedade. Solicitou-se que os participantes ordenassem em escala crescente, dez diferentes alvos organizacionais, oferecendo como alternativa: (a) maximização do lucro no período; (b) crescimento sustentado em longo-prazo; (c) liderança de mercado; (d) controle de custos, produtividade, eficiência; (e) desenvolvimento de know-how; (f) otimização do ambiente de trabalho; (g) desenvolvimento de boas relações com governo / autoridades; (h) desenvolvimento de projetos orientados à responsabilidade social; (i) desenvolvimento de relações de parceria com fornecedores; (j) desenvolvimento de projetos orientados à responsabilidade com o meio-ambiente.

A fim de facilitar a distinção das prioridades das empresas, não poderia haver empate nas respostas, sendo solicitado aos participantes atribuir 1 para 0 alvo mais prioritário e 10 para o alvo menos prioritário.

Para apurar os resultados foi utilizada média aritmética simples da ordem de prioridades informada pelos participantes. Assim, o melhor resultado possível seria 1, caso todos os participantes tivessem assinalado máxima prioridade a um referido alvo, e 10, caso todos os participantes tivessem assinalado mínima prioridade. Os resultados foram arredondados na quarta casa depois da vírgula, para facilitar o entendimento.

Questão 6: Quais são os alvos prioritários na sua empresa? Vide Tabela 90.

Conforme já mencionado, o BSC propõe-se a trazer equilíbrio entre o foco em resultados financeiros de curtoprazo e foco em investimentos em alvos não-financeiros de longo-prazo. Exemplos de alvos de longo-prazo são: investimento em ações que visam à retenção e aquisição de novos clientes, eficiência nas operações a fim de atender os clientes com qualidade, treinamento de funcionários para melhorar a eficiência operacional etc.

A necessidade de equilibrar o curto-prazo ao longoprazo, apresenta-se mais acentuadamente nas empresas abertas, uma vez que os resultados encontrados reforçam a idéia de que tal grupo de empresas é mais voltado a resultados financeiros imediatos. Infere-se que a explicação para tal fenômeno seja a necessidade de atender às expectativas dos acionistas, maximizando os resultados das demonstrações contábeis a cada trimestre.

As empresas fechadas, por outro lado, revelaram-se focadas prioritariamente no crescimento sustentado de longo-prazo. Infere-se que esse foco no longo-prazo ocorra em função da cultura organizacional, que estaria associada a uma predisposição dos proprietários de quotas ou ações de empresas fechadas a pensar em longo-prazo.

$A$ visão mais voltada ao curto-prazo nas empresas com ações na Bolsa de Valores poderia ser conseqüência da visão de curto-prazo de seus acionistas voltada para a valorização de suas ações no mercado de capitais.

Tabela 8 Uso do BSC X Uso do Planejamento Estratégico ${ }^{13}$

\begin{tabular}{c|c|c} 
& BSC & Planejamento Estratégico \\
Não & $42,9 \%$ & $3,9 \%$ \\
\hline $\operatorname{Sim}$ & $57,1 \%$ & $96,1 \%$
\end{tabular}

13 "Não" indica que a empresa "nenhum grau de contribuição" para o alinhamento dos indicadores à estratégia (questão 3), divulgação da estratégia (questão 4), e apoio na tomada de decisões (questão 5). "Sim" indica que a empresa assinalou no mínimo "pouco grau de contribuição" para as questões 3, 4, ou 5. 
Tabela 9 || Prioridade dos alvos das organizações pesquisadas

\begin{tabular}{|c|c|c|c|c|c|}
\hline & \multirow{2}{*}{$\begin{array}{c}\text { Tipo de Sociedade } \\
\text { Alvo / Meta }\end{array}$} & \multicolumn{2}{|c|}{ Capital Aberto } & \multicolumn{2}{|c|}{ Capital Fechado } \\
\hline & & $\begin{array}{l}\text { Média Aritmética } \\
\text { dos Resultados }\end{array}$ & $\begin{array}{l}\text { Classificação } \\
\text { da Prioridade }\end{array}$ & $\begin{array}{l}\text { Média Aritmética } \\
\text { dos Resultados }\end{array}$ & $\begin{array}{l}\text { Classificação } \\
\text { da Prioridade }\end{array}$ \\
\hline a) & $\begin{array}{l}\text { Maximização do lucro no } \\
\text { período }\end{array}$ & 2,5588 & 1 & 2,5116 & 2 \\
\hline b) & $\begin{array}{l}\text { Crescimento sustentado } \\
\text { em longo prazo }\end{array}$ & 2,8824 & 2 & 2,3953 & 1 \\
\hline c) & Liderança de Mercado & 3,9118 & 4 & 3,8837 & 4 \\
\hline d) & $\begin{array}{l}\text { Controle de custos, } \\
\text { produtividade, eficiência }\end{array}$ & 3,0588 & 3 & 3,1163 & 3 \\
\hline e) & $\begin{array}{l}\text { Desenvolvimento de } \\
\text { know-how }\end{array}$ & 5,5882 & 5 & 5,5349 & 5 \\
\hline f) & $\begin{array}{l}\text { Otimização do ambiente } \\
\text { de trabalho }\end{array}$ & 6,8824 & 7 & 6,7907 & 7 \\
\hline g) & $\begin{array}{l}\text { Relações com governo / } \\
\text { autoridades }\end{array}$ & 8,3824 & 10 & 8,5116 & 10 \\
\hline h) & $\begin{array}{l}\text { Projetos orientados à } \\
\text { responsabilidade social }\end{array}$ & 8,2941 & 9 & 8,2558 & 9 \\
\hline i) & $\begin{array}{l}\text { Relações de parceria com } \\
\text { fornecedores }\end{array}$ & 6,0000 & 6 & 6,1395 & 6 \\
\hline j) & $\begin{array}{l}\text { Projetos orientados à resp. } \\
\text { com o meio ambiente }\end{array}$ & 7,4118 & 8 & 7,8605 & 8 \\
\hline
\end{tabular}

\section{CONCLUSÕES}

A partir da pesquisa de campo, verificou-se que tanto o grau de importância atribuído aos fatores financeiros para a tomada de decisão, quanto o nível de implementação desses indicadores, são significativamente maiores nas empresas abertas do que nas empresas fechadas. Essa constatação corrobora a pesquisa de Pessanha e Prochnik (2004), que encontraram predominância dos indicadores financeiros em empresas que haviam implementado o BSC.

Percebe-se que as características do BSC, voltadas à maximização do resultado aos acionistas, conforme visto no referencial teórico, são aderentes às características das empresas abertas, uma vez que é justamente nesse tipo de organização que há maior desequilíbrio entre fatores financeiros e não-financeiros, conforme visto na Análise de Dados.

Com relação aos alvos prioritários apontados pelas empresas abertas e fechadas, verificou-se que ambos são muito semelhantes. Constatou-se, contudo, que apesar de semelhantes, o grupo de empresas abertas informou que, dentre os dez objetivos apresentados como alternativa, seu objetivo prioritário é a "Maximização do lucro no período". Já o grupo de empresas fechadas informou que seu objetivo prioritário é o "Crescimento sustentado a longo-prazo".

Essa é uma revelação importante demonstrada pela pesquisa, uma vez que se confirma que de fato as empresas abertas são focadas prioritariamente em resultados financeiros de curto-prazo, supostamente para atender às expectativas dos acionistas. As empresas fechadas, por outro lado, não sofrendo pressão por parte desses acionistas para apresentar demonstrações contábeis trimestrais, objetivam o crescimento a longo-prazo.

Constatou-se, neste estudo, que diversos pesquisadores, encontraram correlação positiva entre o uso de indicadores não-financeiros e desempenho organizacional. Assim, a pesquisa revela que a maior aderência do BSC às empresas abertas é coerente com a idéia de que o uso de indicadores não-financeiros pode trazer benefícios à organização, uma vez que Kaplan e Norton (2000) apresentam o instrumento como solução para o foco excessivo das empresas em decisões de curto-prazo baseadas predominantemente em indicadores financeiros. Como as empresas fechadas informaram foco prioritariamente voltado ao "Crescimento sustentado a longo-prazo", supostamente por questões culturais, infere-se que o BSC não seria tão eficaz nesse grupo de empresas, uma vez que as empresas fechadas já apresentaram maior equilíbrio entre indicadores financeiros e não-financeiros.

Quanto à comparação do uso do BSC com o uso do EVA / VBM, bem como do Planejamento Estratégico, percebeu-se que há uma aderência significativamente superior do BSC nas empresas abertas. Verificou-se, também, comportamento semelhante com relação ao EVA / VBM, fato coerente com o referencial teórico, uma vez que se demonstrou que ambos os instrumentos têm características voltadas à maximização dos aspectos financeiros, bem como à maximização do valor do acionista. Em contrapartida, a Análise dos Dados demonstrou que o Planejamento 
Estratégico é mais utilizado pelas empresas fechadas. Infere-se que isso ocorra, uma vez que muitas das empresas abertas que utilizavam o Planejamento Estratégico, passaram a utilizar o BSC quando do seu surgimento, ou de forma conjunta, ou descartando o instrumento mais antigo, uma vez que ambos se propõem a estabelecer estratégias que possibilitem alcançar metas de longo-prazo. Não se verificou o mesmo comportamento nas empresas fechadas, supostamente devido ao fato de que, conforme visto, tais organizações não apresentam um "desequilíbrio" entre aspectos financeiros e não-financeiros tão grande quanto as empresas abertas, o que se traduziria em uma menor necessidade de "equilibrar" os mencionados aspectos.

\section{Referências}

ACKOFF, R. L. Planejamento Empresarial: São Paulo: Atlas, 1980. 114p.

ANSOFF, I. Comment on Henry Mintzberg's Rethinking Strategic Planning. Long Range Planning. London, v. 27, n. 3, p. 31-32, 1994.

BANKER, R.; POTTER, G.; SRINIVASAN, D. An Empirical Investigation of an Incentive Plan that Includes Nonfinancial Performance Measures. The Accounting Review, v. 75, n. 1, p. 65-92, Jan. 2000

COPELAND, T.; KOLLER, T.; MURRIN, J. Valuation: Measuring and managing the value of companies. New York: John Wiley \& Sons, 1995 $558 \mathrm{p}$.

DAVIS, S.; ALBRIGHT, T. An Investigation of the Effect of Balanced Scorecard Implementation of Financial Performance. Management Accounting Research, v. 15, n. 2, p. 135-153, Jun. 2004.

DEARDEN, J. The Case Against ROI Control. Harvard Business Review, Boston, v.47, n.3, p.124-135, May/June, 1969.

DUPONT Heritage. Site Intitucional da Companhia DuPont - Disponível em: $<$ http://heritage.dupont.com/>. Acesso em 03 maio 2005.

GUIMARÃES, R. C.; CABRAL, J. A. S.. Estatística. Lisboa: McGraw-Hill, 1998. 621 p.

ITTNER, C. D.; LARCKER, D. F.; RANDALL, T. Performance Implications of Strategic Performance Measurement in Financial Services Firms. Accounting, Organizations and Society, Oxford, v. 28, n. 7 e 8, p. 715-741, Out/Nov 2003.

JOHNSON, T. H.; KAPLAN, R. S. Relevance Lost. Boston: Harvard Business School, 1987. 239 p.

KAPLAN, R. S.; NORTON, D. P. The Balanced Scorecard: translating strategy into action. Boston: Harvard Business School Press, 1996. 344 p.

The Strategy-Focused Organization: how Balanced Scorecard companies thrive in the new business environment. Boston: Harvard Business School Press, 2000. 457 p.

FONSECA, J. S.; MARTINS, G. A. Curso de Estatística. São Paulo: Atlas, 1996. 320 p.

LAWSON, R.; STRATTON, W.; HATCH, T. The benefits of a scorecard system: A new North American study explains how balanced scorecard users get their money's worth. CMA Management. Hamilton, v. 77, n. 4, p. 24-26, Jun/Jul 2003.

MALINA M. A.; SELTO, F. H. Communicating and Controlling Strategy: An Empirical Study of the Effectiveness of the Balanced Scorecard. Journal of Management Accounting Research. Sarasota. v. 13, p. 47-90, 2001.

MINTZBERG, H. The Fall and Rise of Strategic Planning. Management Accounting Research, Boston. v. 72, n. 1, p. 107-114, Jan/Fev 1994.

NORREKLIT, $H$. The Balance on the Balanced Scorecard: a critical analysis of some of its assumptions. Management Accounting Research, v. 11, p. $65-88,2000$.

OTLEY, D. Performance Management: a framework for management control systems research. Management Accounting Research, Kidlington, v. 10, n. 4, p. 363-382, Dez 1999.

PESSANHA D. S.; PROCHNIK; V. Obstáculos à Implementação do Balanced Scorecard em Três Empresas Brasileiras In: XXVIII ENCONTRO DA ANPAD, Curitiba, 2004.

ROSS, S. A.; WESTERFIELD, R. W.; JAFFE, J. F. Administração Financeira. São Paulo: Atlas, 1995. 689 p.

SIMON H. A. The New Science of Management Decision. New York: Harper \& Brothers Publishers, 1960

STEWART III, G. B. The Quest for Value: the EVA management guide. New York: Harperbusiness, 1991. 781 p.

WEIMER; J; PAPE, J. C. A Taxonomy of Systems of Corporate Governance. Corporate Governance, Blackwell, v. 7, n. 2, p. 152-166, Abr 1997.

\section{NOTA - Endereço dos autores}

Universidade do Vale do Rio dos Sinos

Centro de Ciências Econômicas

Av. da Unisinos, 950

São Leopoldo - RS

93022-000 